\title{
NUMERICAL STUDY OF THE HYDRODYNAMIC CHARACTERISTICS IN AN AGITATED TANK WITH SIDE-ENTRY MIXER: THE EFFECT OF STIRRER ENTRY ANGLE
}

\author{
Ni'am N. Fathonah ${ }^{1}$, Tantular Nurtono ${ }^{1}$, Kusdianto $^{1}$, Suci Madhania ${ }^{1}$, Wahyudiono ${ }^{2}$, \\ Sugeng Winardi $1^{*}$ \\ ${ }^{1}$ Department of Chemical Engineering, Institut Teknologi Sepuluh Nopember, Kampus ITS, Sukolilo, \\ Surabaya 60111, Indonesia \\ ${ }^{2}$ Department of Materials Process Engineering, Nagoya University, Furo-cho, Chikusa-ku, Nagoya \\ 464-8603, Japan
}

(Received: July 2018 / Revised: October 2018 / Accepted: April 2019)

\begin{abstract}
The main objective of this work is to study the effect of stirrer entry angle $\beta$ on the hydrodynamic characteristics in an agitated tank with side-entry mixer (side-entry mixing tank) using the CFD simulation method. For validation purposes, the simulation results were compared with the experimental results. Qualitatively, it was found that there was a similar fluid flow in the simulation and experiment results. The agitated tank system consisted of a $40 \mathrm{~cm}$ diameter cylindrical tank and a three-blade marine propeller with $4 \mathrm{~cm}$ diameter. The working fluid was water, with a liquid height of $40 \mathrm{~cm}$. The rotational speed varied between 100-400 rpm, with the stirrer entry angle $(\beta)$ set at $0^{\circ}, 10^{\circ}$ and $15^{\circ}$ (right-hand side). The modelling configurations used in the simulation were an RNG Standard $k-\varepsilon$ model as a turbulence model, coupled with a Multiple Reference Frame (MRF) for the propeller motion approach method in transient conditions. The results show that simulation configuration MRF-RNG $k-\varepsilon$ produced realistic results to describe the hydrodynamic characteristics in the side-entry stirred tank. This is supported by the simulation results, which qualitatively produced similar flow patterns in the simulation and experiment. In the quantitative analysis, at higher rotational speeds the circulation flow formed tended to be pushed further from the impeller discharge, which is supported by the average velocity experimental data. Average velocity in the tank had a tendency to increase as the $\beta$ increased. The predicted average velocities (in $\mathrm{m} / \mathrm{s}$ ) were $0.0175,0.0185$ and 0.0197 at $\beta 0^{\circ}, 10^{\circ}$ and $15^{\circ}$ respectively, at a constant rotational speed (400 rpm). Larger $\beta$ produced high tangential velocity, leading to a strong circulation flow. Applications of this side-entry mixing tank include those in large scale reactors and storage tanks to maintain the homogeneity of the material inside.
\end{abstract}

Keywords: CFD; MRF; RNG $k$-e; Side-entry angle; Side-entry mixer

\section{INTRODUCTION}

Agitated tanks with side-entry mixers are widely used in the pulp and paper industries, flue gas desulphurization, the petroleum industry, and as bio-digesters in biogas plants. These agitators provide rugged reliability, application versatility, and easy, economical installation, operation and maintenance. The main feature of an agitated tank with a side-entry mixer is the large tank size, with a small impeller diameter. The ratio of the impeller diameter to the tank diameter is

\footnotetext{
*Corresponding author's email: swinardi@chem-eng.its.ac.id, Tel. +62-31-5946240, Fax. +62-31-5999282, Permalink/DOI: https://doi.org/10.14716/ijtech.v10i3.2925
} 
relatively small compared to an agitated tank with top-entry mixer.

The types of stirrer used depend on the desired process outcome, process requirements, and the scale or volume of the material to be processed. The greatest advantage of the type of stirrer employed in the mixing process using a side-entry stirred tank is that it generates axial flow, since the desired flow pushes the fluid toward the front of the impeller shaft, allowing the fluid to circulate to all parts of the tank after colliding with the tank wall. This axial-type stirrer is also highly recommended for controlled flow operations, such as blending/mixing operations, to suspend solids in the liquid, and to accelerate heat transfer (Joshi et al., 2011). Based on previous research, the type of stirrer most widely used in side-entry stirred tanks is a type of propeller and axial turbine (IBT or PBT). These axial impellers are also highly recommended for controlled flow operations, such as blending/mixing operations, to suspend solids in the liquid, and to accelerate heat transfer.

The performance of an agitated tank with a side-entry mixer, however, will depend on the location, position, the speed, and number of impellers used. The location and position of the impeller are determined by the impeller entry angle $(\beta)$; i.e. the angle between the impeller shaft and the center line of the cylindrical tank, and the distance of the impeller from the bottom and wall of the tank. As a result, the flow pattern produced becomes very complicated and has unstable characteristics in space and time.

The effect of $\beta$ on fluid flow in agitated tanks with side entry angle was first investigated experimentally by Kipke (1984) in cylindrical tanks with diameters of $0.7 \mathrm{~m}$ and $1.4 \mathrm{~m}$. He showed that the most effective agitation process to achieve good homogeneity was obtained with $\beta=7-10^{\circ}$, depending on tank diameter. Subsequently, several studies have further analysed fluid flow characteristics in industrial-scale agitated tanks with side-entry mixers using CFD-based simulations. Dakhel and Rahimi (2004) examined a side-entry stirred tank used for the storage of crude oil with a diameter of $44 \mathrm{~m}$. The model configuration used in the simulation was MRF and RNG $k-\varepsilon$., Fang et al. (2011) investigated a side-entry stirred tank with multiple agitators with the same configuration of MRF and RNG $k-\varepsilon$. Wu (2012) established an optimum angle in the $30^{\circ}-$ $40^{\circ}$ range for a cylinder tank with diameter $>40 \mathrm{~m}$. The effect of impeller entry angles on mixing performance in large-scale biogas reactors $(\mathrm{D}=16 \mathrm{~m})$ was investigated by Xinxin et al. (2018). Validation of the results of the simulation in these works can only be carried out qualitatively and globally, using the limited data that can be obtained at the plant site.

In a simulation, an appropriate approach is needed to obtain more realistic results. In previous works, Lane et al. (2000) compared the sliding mesh (SM) and multiple reference frame (MRF) models to simulate fluid flow in a top-entry stirred tank with a disc turbine as a stirrer. Their results show that the MRF provides a more realistic flow pattern and kinetic energy value, and that its energy dissipation had a smaller error. Winardi et al. (2013) used a combination method of two configurations of turbulence and impeller motion modelling, and MRF with $k-\varepsilon$ in steady mode followed by SM-LES in transient mode, to characterize the flow patterns that occur in sideentry stirred tanks using PBT. In the following year, Winardi et al. (2014) conducted simulations with the same method for the same agitated vessel geometry, but with a different type of impeller, namely a marine propeller. Fathonah et al. $(2017 ; 2018)$ used an MRF modelling configuration with the $k-\varepsilon$ model to simulate a side-entry stirred tank with an IBT. Their results showed qualitatively that the MRF was able to describe a good flow pattern clearly and was almost similar to the experimental results. Dakhel and Rahimi (2004) examined an agitated tank with a sideentry mixer used as crude oil storage tank with a diameter of $44 \mathrm{~m}$, using MRF and RNG $k-\varepsilon$. Fang et al. (2011) also investigated an agitated tank with a side-entry mixer and multiple impellers, with MRF and RNG $k-\varepsilon$. Madhania et al. (2018) obtained good simulation results from the mixing of liquid-liquid with a very large viscosity difference in an agitated tank with a side- 
entry mixer and conical bottom. The turbulence model used in CFD simulation plays an important role in predicting the exact flow conditions in a side-entry stirred tank, because not all turbulence models can be used in all operating conditions (Daryus et al., 2016). This research is a simulation study, validated with experimental data. Observation of the flow pattern that occurs as a result of changes in the horizontal entry angle of the propeller, rotational speed and variations in flow patterns, including the phenomenon of MI, are examined. The effect of impeller entry angle $\beta$ on hydrodynamic characteristics in an agitated tank with side entry marine propeller in laboratory conditions was studied using the CFD simulation approach with the MRF-RNG $k-\varepsilon$ model.

\section{METHODS}

\subsection{Mathematical Model}

The phenomenon of flow can be modelled by a mathematical version of the continuity equation (law of mass conservation) and the momentum equation (law of momentum conservation). The continuity equation for a compressible fluid at unsteady state for incompressible flow with density value $(\rho)$ is constant, is given below:

$$
\frac{\partial \rho}{\partial t}+\nabla(\rho v)=0
$$

Flow in the stirred tank is assumed to be three dimensional and steady; the working fluid is an incompressible Newtonian fluid; there is no change in temperature during the mixing process; and the system is a single-phase fluid.

In the previous study, mentioned in introduction section, the most widely used model for the turbulence model is RNG $k-\varepsilon$, and the results obtained show that this can produce satisfactory results when compared with the experimental data. RNG is a form of renormalization of the Navier Stokes equation, which explains the smaller motion effects that cannot be calculated by the latter. In the $k-\varepsilon$ standard model, eddy viscosity is determined from a single scale of turbulence, resulting in the calculated turbulence diffusion on a given scale. However, the actual motion on a small scale still has a significant influence on the calculation of turbulence diffusion. The RNG approach, which can mathematically be used to derive a turbulence model similar to $k$ $\varepsilon$, results in a modified form of the equation (equation $\varepsilon$ ), thus extending the range of the calculation of turbulence diffusion to a small motion change. The transport equations for $k$ and $\varepsilon$ that have been modified (Yakhot et al., 1992) are:

$$
\begin{gathered}
\frac{\partial}{\partial t}(\rho k)+\frac{\partial}{\partial x_{i}}\left(\rho k u_{i}\right)=\frac{\partial}{\partial x_{j}}\left[\left(\mu+\frac{\mu_{t}}{\sigma_{k}}\right) \frac{\partial k}{\partial x_{j}}\right]+\mathrm{P}_{k}-\rho \varepsilon \\
\frac{\partial}{\partial t}(\rho \varepsilon)+\frac{\partial}{\partial x_{i}}\left(\rho \varepsilon u_{i}\right)=\frac{\partial}{\partial x_{j}}\left[\left(\mu+\frac{\mu_{t}}{\sigma_{\varepsilon}}\right) \frac{\partial \varepsilon}{\partial x_{j}}\right]+c_{1 \varepsilon} \frac{\varepsilon}{k} \mathrm{P}_{k}-c_{2 \varepsilon}^{*} \rho \frac{\varepsilon^{z}}{k}
\end{gathered}
$$

where

$$
c_{2 \varepsilon}^{*}=c_{2 \varepsilon}+\frac{c_{\mu} \eta^{3}\left(1-\frac{\eta}{\eta_{0}}\right)}{1+\beta^{\prime} \eta^{3}}
$$

The constant value in the equation is derived explicitly (except the $\beta$ ' constant) and becomes the following: $C_{\mu}=0.0845 ; \sigma_{k}=0.7194 ; \sigma_{\varepsilon}=0.7194 ; C_{\varepsilon 1}=1.42 ; C_{\varepsilon 2}=1.68 ; \eta_{0}=4.38 ; \beta^{\prime}=0.012$. 


\subsection{Simulation Method}

Hydrodynamic characteristics in side-entry stirred tanks are influenced by several factors, such as the type of stirrer used, the rotating speed of the stirrer, the mounting position of the stirrer, and the stirrer diameter. Although the stirrer is generally installed close to the bottom of the tank, the direction of the impeller shaft can also horizontally influence the flow characteristics in the stirred tank itself. Simulation was performed using CFD ANSYS® ${ }^{18.2}$ Academic Package software. Geometry modelling was conducted using Design Modeller ${ }^{\circledR}$, with the the number of grids and nodes determined using ANSYS Meshing®. The simulation was run using a workstation (HP Z640, 3.5GHz with 8GB RAM). The tank geometry has cylinder diameter $\mathrm{D}=$ $40 \mathrm{~cm}$ and liquid height $\mathrm{H}=40 \mathrm{~cm}$. The stirrer used was a marine propeller (3 blades) with a diameter of $\mathrm{d}=4 \mathrm{~cm}$ (ratio $\mathrm{d} / \mathrm{D}=0.1$ ). The propeller geometry itself was made in exactly same way as that used in the experiment, as shown in Figure 1a.

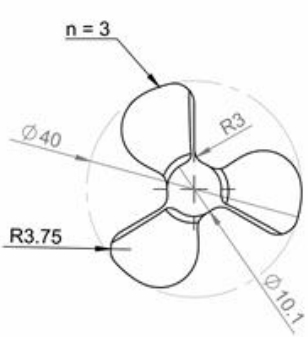

(a)

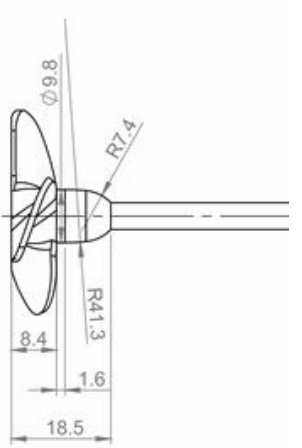

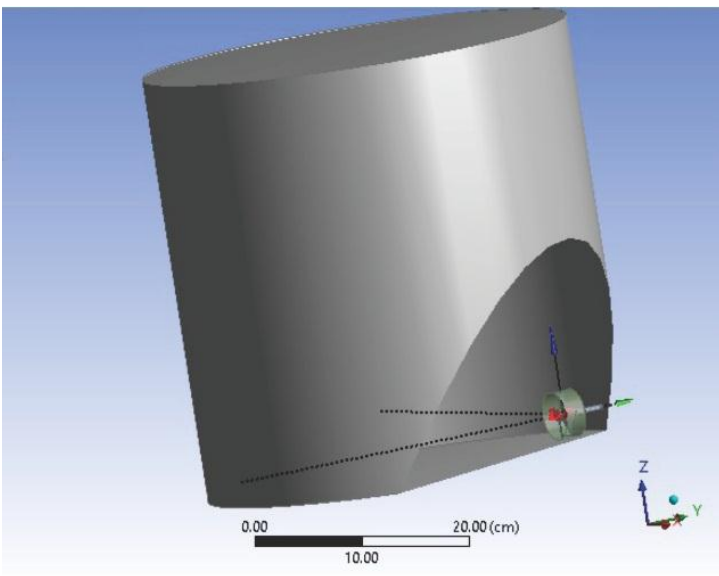

(b)

Figure 1 (a) Dimension (mm) of the marine propeller; (b) tank geometry and propeller zone separated by a cylindrical interface

The propeller geometry is somewhat complex because of the slope and curvature of the blade, therefore the meshing method chosen was a grid with a combination of tetrahedral mesh and prisms, as shown in Figure 2. Tetrahedral mesh is more appropriately applied to complex geometries, and has many narrow slits, as in propellers, because the shape of the grid can instantly adjust to the space.

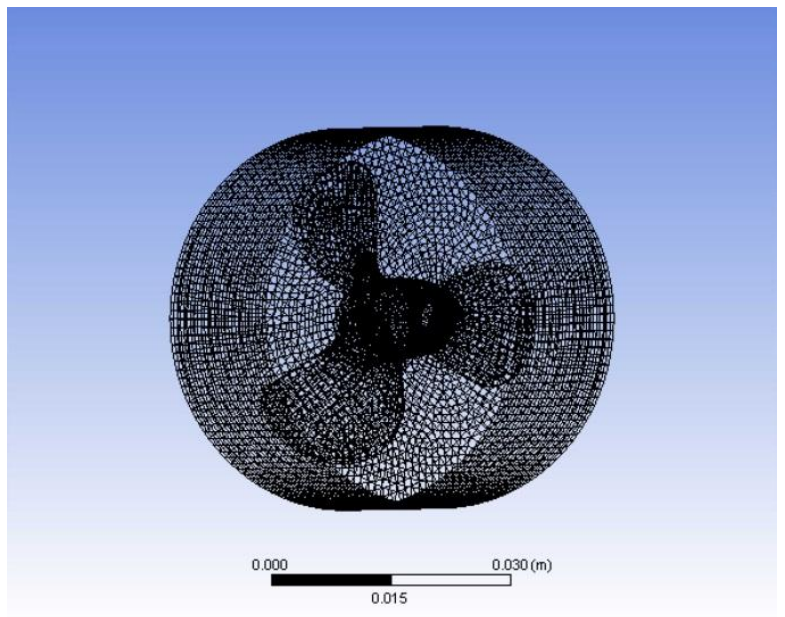

Figure 2 Grid division for the moving zone 
The approach used for the propeller motion was MRF, so the tank volume was divided into two zones: the inner zone (the rotating part where the propeller is located); and the outer zone (the zone outside the interface covering all parts of the tank). Both zones were limited by a cylindrical interface, as shown in Figure 1b. These two zones are referred to as the moving zone (inner) and stationary zone (outer). The diameter and thickness of the moving zone were $0.0475 \mathrm{~m}$ and 0.03 $\mathrm{m}$, respectively.

There is no specific reference for determining the diameter and thickness of the moving zone, since it does not significantly affect the external flow of the interface. A perfect fit or slightly larger form of moving zone than a propeller is not vital, as long as the zone covers all of its propeller geometry. The origin coordinates of the geometry are at the center of the tank bottom $(0,0,0)$ and the propeller shaft at the coordinates $(0,0.2745,-0.2)$, and the $\mathrm{z}$ axis is the axis of the tank. In this study, the propeller is mounted from the side with horizontal angle variation $(\beta)$ to the right-hand side of it of $0^{\circ},-10^{\circ}$ and $-15^{\circ}$ (the negative angles are based on the coordinates used when drawing the tank geometry, and will be subsequently written without the negative signs in results and discussion section). Therefore, for the arrangement of the axis of propeller rotation direction at $\mathrm{x}=\sin \beta$ and $\mathrm{z}=\cos \beta$, the setting applies to the moving zones, shafts and propellers. The settings of the origin and direction axis are important, as they will affect the flow direction of the impeller discharge section. A less precise directional axis will result in a proposed outflow propeller flow going in the opposite direction. The flow pattern formed from a propellertype stirrer that should be axial may be transformed into radial in the simulation simply by errors in the definition of the axis direction.

Other definitions of boundary conditions that need to be regulated are the tank wall and the propeller shaft. Both are considered to have a smooth surface, so that these set as a no-slip condition, the liquid surface is considered unstable when the shear stress is zero, defined as the symmetry surface. The variable propeller rotational speeds in this study were 100, 200, 300 and $400 \mathrm{rpm}$, with Reynolds numbers of 2989.88, 5980.45, 8970.78 and 11960.67, respectively. These Reynolds numbers are included in the transition-turbulent regime in a stirred vessel (Galletti et al., 2004). The simulation ran with a time step of 0.0004746 (based on the calculation rules in determining the time step in FLUENT) and was considered convergent when all the residual parameters were worth less than $1 \times 10^{-3}$. In addition to observing the indication of the convergence of the residual parameters, the convergence history of the torque on the shaft and propeller until the value is constant is also seen.

\section{RESULTS AND DISCUSSION}

Qualitatively, the easiest way to observe hydrodynamic characteristics in a side-entry stirred tank is from the flow pattern produced inside the vessel. In this research, the macro scale flow structures shown as a result of simulation were the mean-time averaged velocity fields were obtained by averaging 10000 measurements for each velocity variable. The flow pattern in a stirred tank is a combination of flow regimes that are dependent on their location in the vessel. For example, areas that are close to the propeller (discharge) will have high flow velocities and tend to have turbulent properties, compared to areas farther from the propeller, especially those located on the surface of the tank, where the flow velocity will be very different (Bittorf \& Kresta, 2000). This situation results in zones without flow, commonly referred to as death zones, in certain parts of the tank. These are zones where the fluid has a very low or almost zero velocity, or where a vortex is formed which remains stationary, so there is no mass transfer. This condition is very unfavourable for achieving an effective mixing process.

Figure 3 shows the flow patterns obtained from the simulation results using configuration RNG $k-\varepsilon$ and MRF for the propeller motion. A marine propeller is a type of stirrer that produces an 
axial flow pattern, in which the fluid flows axially from the impeller axis towards the tank wall. The main flow form is one loop circulation, as well as the type of flow pattern produced by IBT in previous studies (Fathonah et al., 2017; Fathonah et al., 2018). This is a characteristic of stirrers with axial flow types in general. Figure 3 also shows that at a low rotational speed $(100 \mathrm{rpm})$ the flow pattern formed is a quick return flow, while at higher speeds the circulation flow that is formed tends to be pushed further from the impeller discharge due to the greater force from the motion of the liquid. The mixing intensity was defined as the average velocity throughout the observation plane shown in Figure 3.

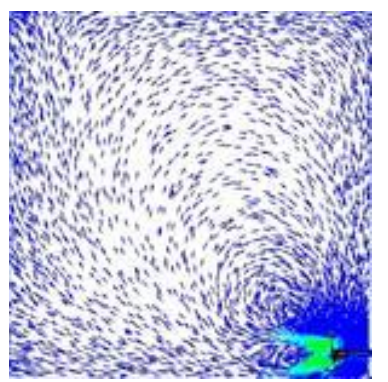

$100 \mathrm{rpm}$

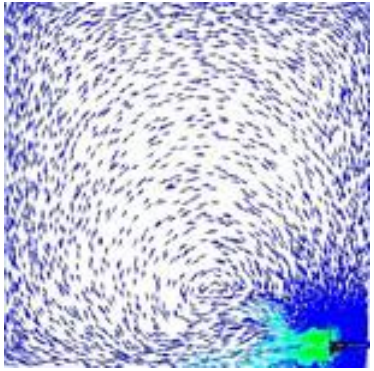

$200 \mathrm{rpm}$

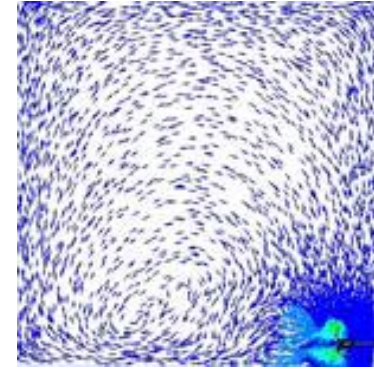

$300 \mathrm{rpm}$

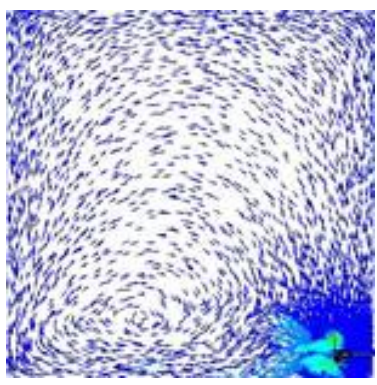

$400 \mathrm{rpm}$

Figure 3 Flow patterns formed at vertical plane observation by the marine propeller for $\beta=10^{\circ}$ (right)

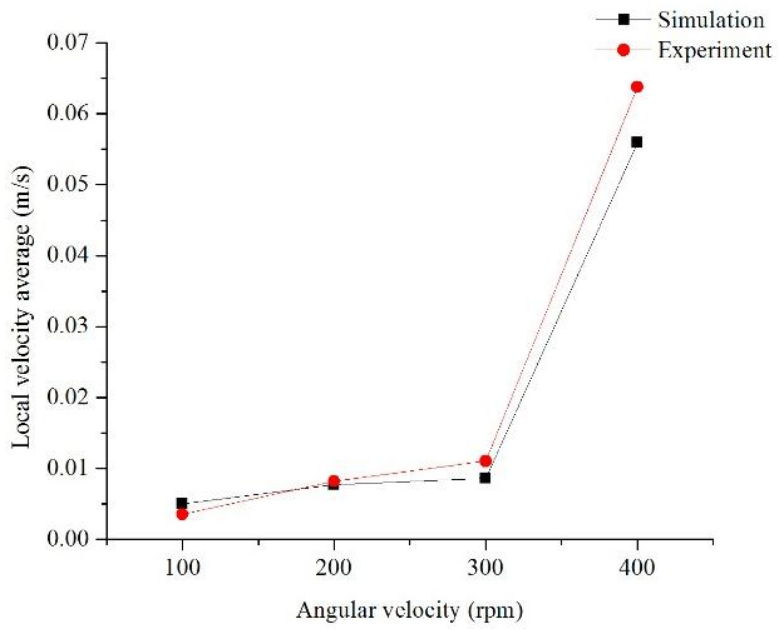

Figure 4 Comparison of the average local discharge stream velocity on a vertical observation plane for $\beta=10^{\circ}$

This conclusion is also supported by the simulation results, which quantitatively show the same tendency as the experimental ones after validation, as shown in Figure 4. Figure 4 shows the average local velocity in the discharge stream propeller area, comparing the simulation results with the experimental ones. The linear velocity in the tank increases with increasing propeller angular velocity. For quantitative analysis purposes, the horizontal observation plane is also aligned with the propeller axis so that it will appear in the circle plane. This makes it easy to analyse the effect of changes in the propeller side-entry angle on the flow velocity in the tank. The $\beta$ variables used are $0^{\circ}, 10^{\circ}$ and $15^{\circ}$ to the right of the propeller shaft horizontally. The average velocity in the tank has a tendency to increase as the $\beta$ increases. The predicted average velocities (in $\mathrm{m} / \mathrm{s}$ ) were $0.0175,0.0185$ and 0.0197 at $\beta 0^{\circ}, 10^{\circ}$ and $15^{\circ}$, respectively, at a constant rotational speed of $\mathrm{N}=400 \mathrm{rpm}$. Larger $\beta$ produced high tangential velocity, leading to a strong circulation flow ( $\mathrm{Wu}, 2012)$. This is also supported qualitatively by the visualization of the velocity contour and streamline in Figure 5. The velocity profile data are the results of simulation 
calculations based on a steady state flow pattern. The velocity contour in Figure $5 \mathrm{~b}$ shows that the areas with increasingly bright colors (blue to green) have a greater velocity. The most significant change seen in Figure $5 \mathrm{~b}$ is the color of the velocity contour near the propeller, which is green at $\beta=10^{\circ}$, whereas at $\beta=0^{\circ}$ it is not.

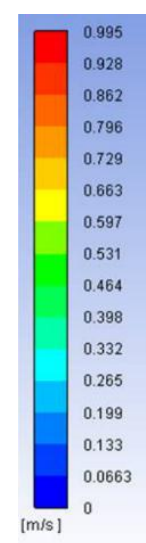

(a)
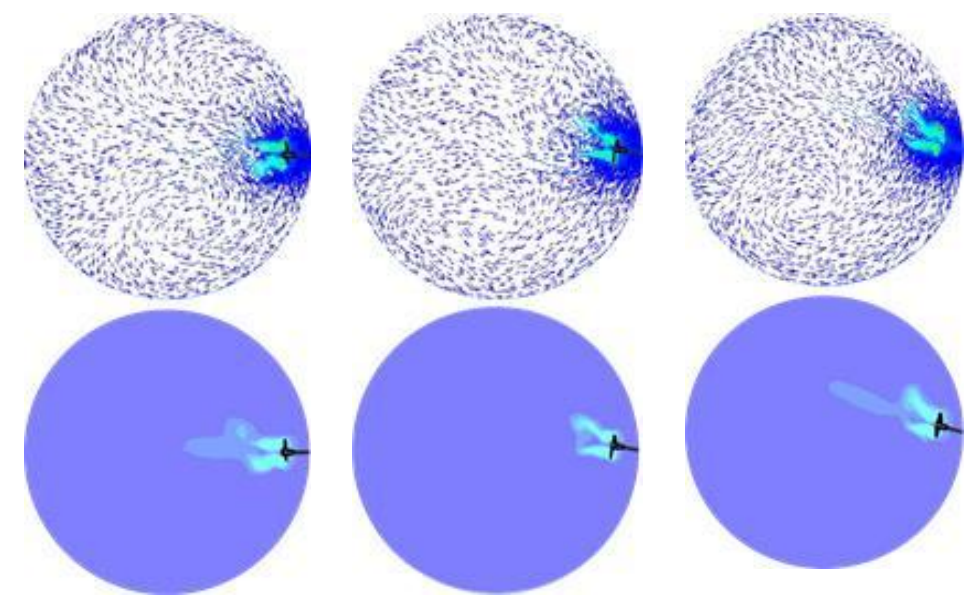

Figure 5 Effect of $\beta$ on flow fields: (a) velocity vector; (b) velocity contour, at a horizontal observation plane of $\mathrm{N}=400 \mathrm{rpm}$ for mixing by the marine propeller

Apart from the contour velocity, the streamline formed as shown in Figure 5a also shows good agreement. The larger $\beta$ produced a circulation flow further away from the propeller discharge. As previously explained, higher velocity will strongly push the circulation flow away from the propeller discharge. Therefore, the motion of the fluid is more likely to reach all parts of the vessel.

(a)
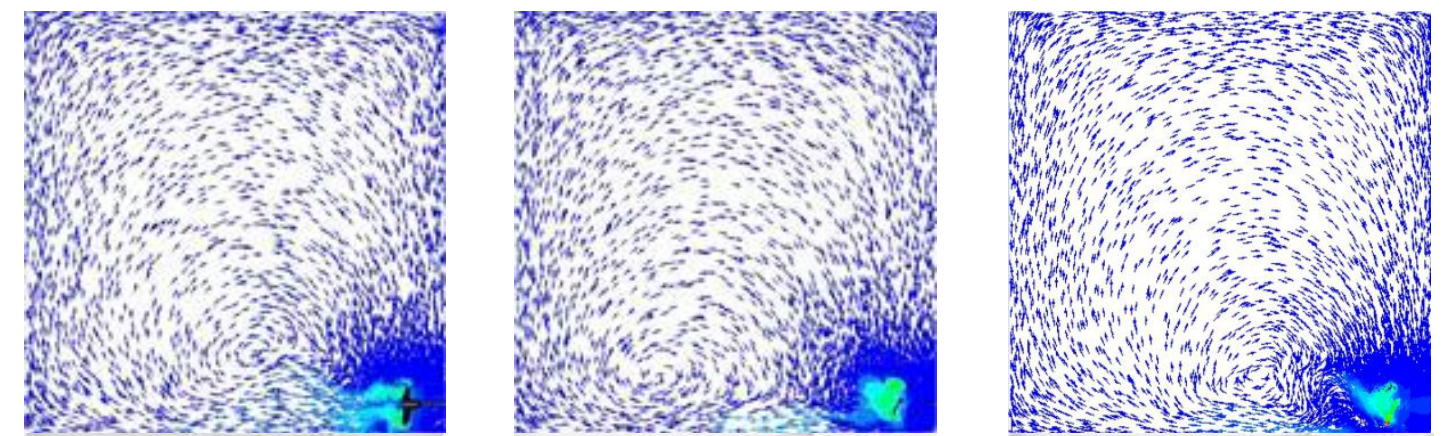

(b)
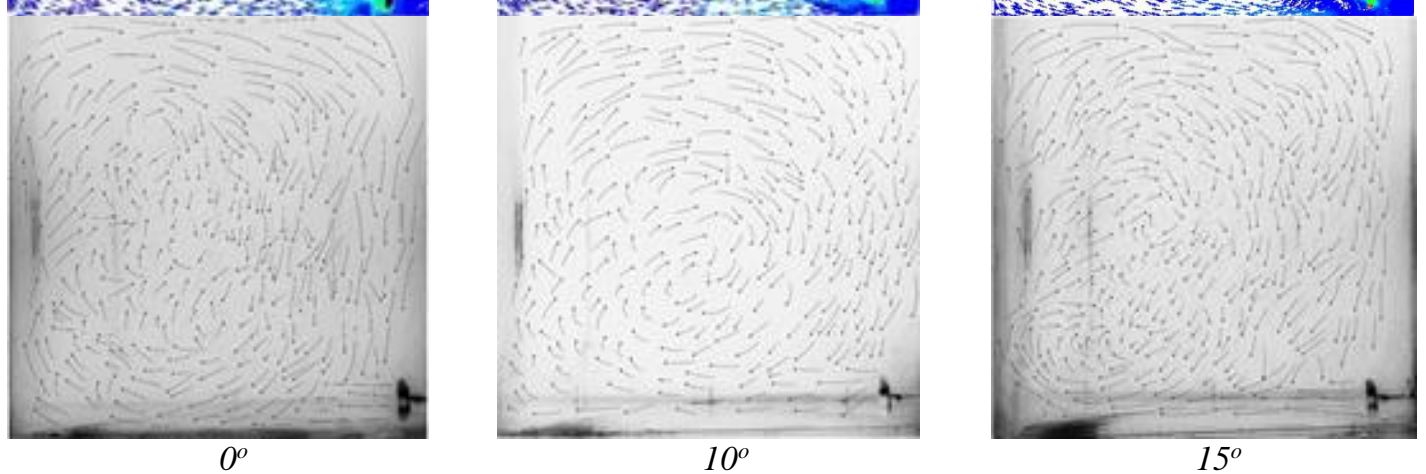

Figure 6 Velocity vector produced by: (a) simulation; (b) experiment, at a vertical observation plane of $\mathrm{N}=300 \mathrm{rpm}$ for mixing by the marine propeller

The streamline from the simulation results also shows a more chaotic flow, which is an irregular form due to the increase in $\beta$. It can be seen in Figure 6 that for the vertical observation plane, 
circulation flow produced with larger $\beta$ shows a more irregular form. Formation of a more chaotic flow with larger $\beta$ is caused by the fact that when $\beta$ is larger, the propeller discharge direction towards the tank wall will become closer. With this closer distance, the fluid that moves from the propeller discharge to the wall at a high velocity will immediately hit the wall, and the faster flow will spread to the right and left-hand sides of the propeller axis. The short time span between discharge flow and flow divided by wall collisions results in the formation of chaotic flow. Such a flow is good for the mixing process because it can reach all parts of the vessel and ensure that the fluid is more quickly mixed and better dispersed.

Another interesting phenomenon that can be observed from the mixing process is that macroinstability phenomena appeared when the mixing process was taking place. These phenomena are three-dimensional and unstable flows that can occur even in symmetrical flow geometries, resulting from the interaction of a symmetrical vortex ring with a free surface, and always accompanied by strong velocity fluctuations in all parts of the mixing tank. Therefore, these phenomena occur in areas that have the greatest average velocity in the vessel, namely those around the front of the discharge propeller, as shown in Figure 7.

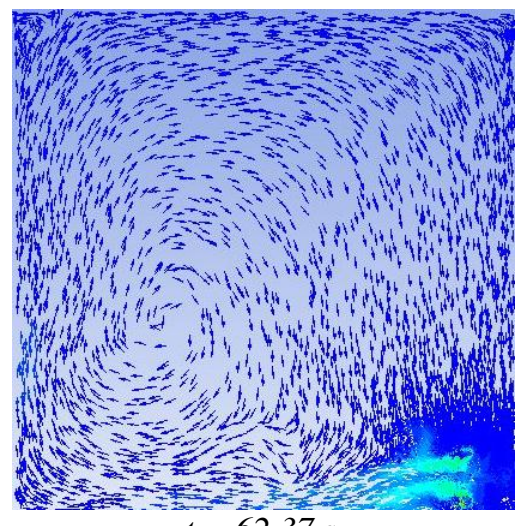

$t=62.37 \mathrm{~s}$

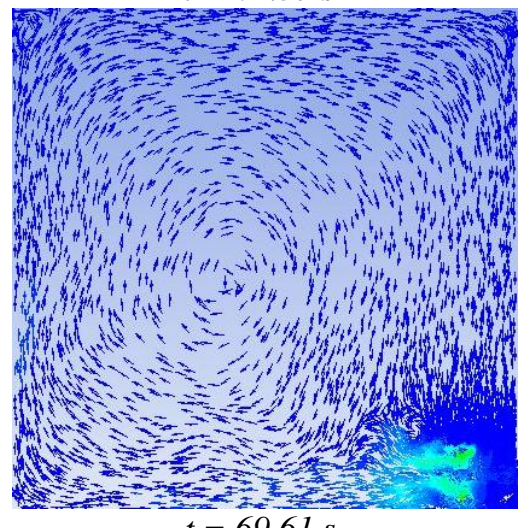

$t=69.61 \mathrm{~s}$

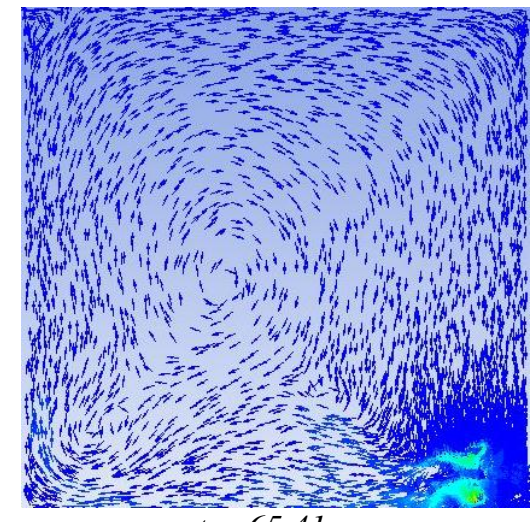

$t=65.41 \mathrm{~s}$

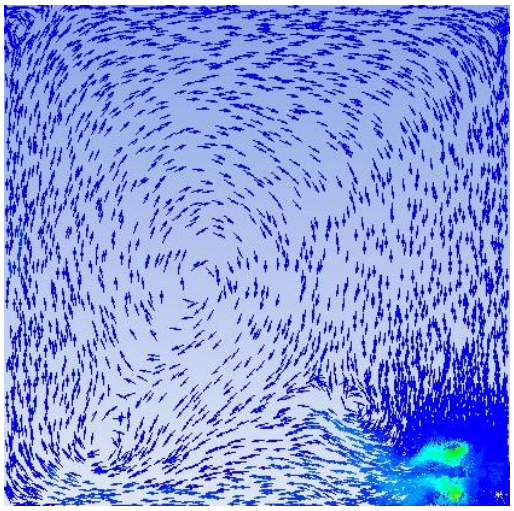

$t=74.48 s$

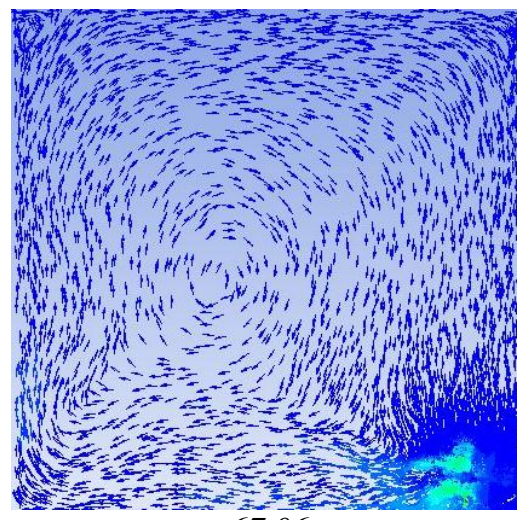

$t=67.06 \mathrm{~s}$

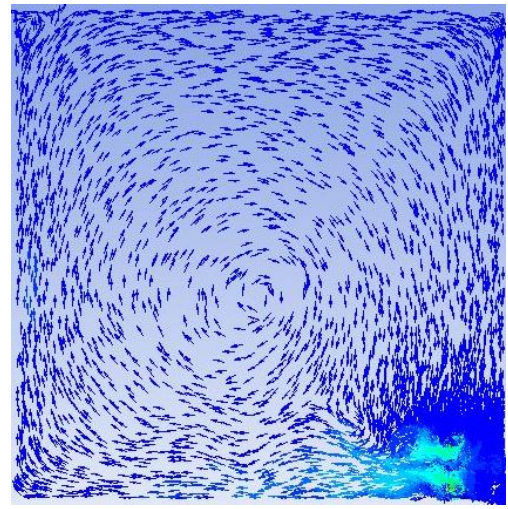

$t=77.66 \mathrm{~s}$

Figure 7 Flow patterns produced at $\beta=0^{\circ}$ and $\mathrm{N}=300 \mathrm{rpm}$

From Figure 7, it can be seen there were significant flow pattern changes over time. Such changes will vary continuously until a cycle of changes in the same flow pattern is formed at a certain time. Like the unstable flow pattern at $t=69.61 \mathrm{~s}$, it appears at $\mathrm{t}=77.66 \mathrm{~s}$. Every new pattern that appears has a lifetime of occurrence of approximately 2 to $5 \mathrm{~s}$. Another pattern besides one loop circulation in the area in front of the propeller discharge near the tank wall as shown in Figure 7 when $\mathrm{t}=65.41 \mathrm{~s}$, the pattern disappeared at $\mathrm{t}=69.61 \mathrm{~s}$ and formed another one in front of the discharge propeller, then began to reappear at $t=74.48 \mathrm{~s}$. The phenomena illustrated by the flow pattern of the simulation results show that they are macro-instability, because the new flow 
patterns have a short frequency of occurrence and a lifetime of more than one propeller rotation $(>0.2 \mathrm{~s})$.

A further application of this side-entry mixing tank is for biogas reactors. Mixing in a biogas reactor, in addition to helping the gas formed from the reaction rise to the liquid surface (as explained in the introduction), also acts as a dispersing substrate, so that it does not settle at the bottom of the tank, which can cause the biodegradation process to be ineffective.

\section{CONCLUSION}

This work has presented a three-dimensional and transient CFD simulation of the hydrodynamic characteristics in an agitated tank with side-entry marine propeller. It has been found that the simulation configuration MRF-RNG $k-\varepsilon$ provided realistic results to describe these characteristics with different impeller entry angles $(\beta)$. For validation purposes, the simulation results were compared with the experimental results. Qualitatively, similar fluid flows were found in the simulation and experiment results. In the quantitative analysis, at higher rotational speeds the developed circulation flow tended to be pushed further from the impeller discharge stream; this was validated by the measured average velocity data. From the research results described in the results and discussion section, the horizontal slope of the propeller entry angle has a significant effect on changes in the hydrodynamic characteristics and flow patterns in the side-entry mixing tank. Average velocity in the tank tends to increase as the impeller entry angle $\beta$ increased. The predicted average velocities were $0.0175,0.0197$ and $0.0182 \mathrm{~m} / \mathrm{sec}$ at $\beta=0^{\circ}, 10^{\circ}$ and $15^{\circ}$ respectively, at constant rotational speed. A larger impeller entry angle $\beta$ produced high tangential velocity, leading to a strong circulation flow. Such a flow is good for the mixing process because it can reach all parts of the vessel.

\section{ACKNOWLEDGEMENT}

The authors are grateful for the financial support provided by the PMDSU research and scholarship grant 2018 from the Directorate of Research and Public Service, Directorate General of Research Strengthening and Development, Ministry of Research, Technology and Higher Education of the Republic of Indonesia, with contract number 818/PKS/ITS/2018. We also extend our gratitude to Mr. M. Murtadho and Ms. Yukh Ihsana for their assistance in the experiment.

\section{REFERENCES}

Bittorf, K.J., Kresta, S.M., 2000. Limits of Fully Turbulent Flow in a Stirred Tank. In: Proceedings $10^{\text {th }}$ European Conference on Mixing, Chapter 3, pp. 17-24

Dakhel, A.A., Rahimi, M., 2004. CFD Simulation of Homogenization in Large-scale Crude Oil Storage Tanks. Journal of Petroleum and Engineering, Volume 43(3-4), pp. 151-161

Daryus, A., Siswantara, A.I., Darmawan, S., Gunadi, G.G.R., Camalia, R., 2016. CFD Simulation of Turbulent Flows in Proto X-3 Bioenergy Micro Gas Turbine Combustor using STD k- $\varepsilon$ and RNG k-E Model for Green Building Application. International Journal of Technology, Volume 7(2), pp. 204-211

Fang, J., Ling, X., Sang, Z.-F., 2011. Experimental and Numerical Studies of the Flow Field in a Stirred Tank Equipped with Multiple Side-entering Agitators. Journal of Chemical Engineering and Technology, Volume 34(10), pp. 1619-1629

Fathonah, N.N., Susanti, A., Nurtono, T., Winardi, S, Machmudah, S., Kusdianto, Widiyastuti, 2017. Modeling Turbulent Flow in a Cylindrical Tank Agitated by Side Entering $45^{\circ}$ Inclined Blade Turbine using Computational Fluid Dynamics (CFD). In: AIP Conference Proceedings, Volume 1840(1) 
Fathonah, N.N., Nurtono, T., Kusdianto, Winardi, S., 2018. Turbulent Flow in a Vessel Agitated by Side Entering Inclined Blade Turbine with Different Diameter using CFD Simulation. In: Journal of Physics: Conference Series, Volume 974(1)

Galletti, C., Paglianti, A., Lee, K.C., Yianneskis, M., 2004. Reynolds Number and Impeller Diameter Effects on Instabilities in Stirred Vessels. An Official Publication of the American Institute of Chemical Engineers (AIChE) Journal, Volume 50(9), pp. 2050-2063

Joshi, J.B., Nere, N.K., Rane, C.V., Murthy, B.N., Mathpati, C.S., Patwardhan, A.W., Ranade, V.V., 2011. CFD Simulation of Stirred Tanks: Comparison of Turbulence Models (Part II: Axial Flow Impellers, Multiple Impellers, and Multiphase Dispersions). The Canadian Journal of Chemical Engineering, Volume 89(4), pp. 754-816

Kipke, K., 1984. Suspension by Side Entering Agitators. Chemical Engineering Processing: Process Intensification, Volume 18(4), pp. 233-238

Lane, G.L., Schwarz, M.P., Evans, G.M., 2000. Comparison of CFD Methods for Modelling of Stirred Tanks. In: Proceedings $10^{\text {th }}$ European Conference on Mixing, Chapter 34, pp. $273-$ 280

Madhania, S., Nurtono, T., Cahyani, A.B., Carolina, Yuswan, M., Winardi, S., Purwanto, W.W., 2018. Mixing Behaviour of Miscible Liquid-liquid Multiphase Flow in Stirred Tank with Different Marine Propeller Instalment by Computational Fluid Dynamic Method. Chemical Engineering Transactions, Volume 56, pp. 1057-1062

Winardi, S., Nurtono, T., Widiyastuti, Machmudah, S., Septiani, E.L., 2013. Flow Patterns Characteristics in Agitated Tank with Side Entering Impeller In: Proceedings SEACMA 2013

Winardi, S., Mubin, S., Pradana, D., Septiani, E.L., Nurtono, T., Machmudah, S., Widiyastuti, 2014. Hydrodynamic Characteristics in Agitated Tank with Marine Propeller Side-entering Mixers based on Computational Fluid Dynamic Study. In: Proceedings $2^{\text {nd }}$ ISFAChE 2014, Volume I06, pp. 181-187

Wu, B., 2012. Computational Fluid Dynamics Study of Large-scale Mixing System with SideEntering Impeller. Engineering Applications of Computational Fluid Mechanics, Volume 6(1), pp. 123-133

Xinxin, L., Yadong, C., Zhenfeng, H., Jingfu, L., Gang, C., Rui, P., 2018. Study on Side-entering Agitator Flow Field Simulation in Large Scale Biogas Digester In: MATEC Web of Conferences, Volume 153(12)

Yakhot, V., Orszag, S.A., Thangam, S., Gatski, T.B., Speziale, C.G., 1992. Development of Turbulence Model for Shear Flow by a Double Expansion Technique. In: AIP Physics of Fluid A, Fluid Dynamic, Volume 4(7), pp. 1510-1521 